\title{
9. Perceptions of quality of life: gender differences across the life course
}

\author{
Jacqueline Scott, Anke C. Plagnol and \\ Jane Nolan
}

\section{INTRODUCTION}

The study of quality of life is in the ascendancy. As the evidence becomes clearer that increasing the purchasing power of citizens does not automatically increase their sense of well-being, there is new interest in how quality of life is perceived. If it is not merely money and good health that matters, then what else is important for the 'good life'? Recent decades have seen a convergence of interest in quality of life research by economists, psychologists, sociologists and philosophers (for example Sirgy et al. 2006). Philosophers have tended to focus on the abstract principles or, more often, the difficulties of arriving at principles that might help guide people's pursuit of happiness. A crude summary of the philosophers' position is that it is tough for people to know what makes a good life. Social scientists are more modest in their aims and tend to focus on the range of so-called 'goods' that may contribute to quality of life. The economists and sociologists are interested in not only how these are distributed across the population, but also how they change across time. The range of possible 'goods' is very wide and includes health (Wilkinson 1996), employment (Gallie 1996), money (Easterlin 2001), time (Gershuny and Halpin 1996), status (Marmot 2004), environment (Bliss 1996) and so on.

Among the most important of these 'goods' are those that are found in the private sphere, particularly in terms of relationships with friends and family. The notion that it is not merely the existence of family relationships but also the quality of family relationships that affect individual well-being is well established (Elliott and Umberson 2004). What is also clear is that trade-offs in the balance between family and work are very different for men and women. The traditional gender division of labour, in which men do the paid work of winning the bread for their loved ones and women busy themselves with unpaid labour of love within the home, may seem 
anachronistic. Nevertheless, in the UK, women's increasing involvement in paid work has not had as much of an impact on gender roles as might have been expected: women still do the bulk of unpaid work, regardless of their employment status. Such gender role differences mean that men and women are starting from somewhat different viewpoints in assessing what matters for their quality of life.

If love and work, as Freud asserted, are the cornerstones of our humanness, and if the balance of family and work are very different for men and women, then it would follow that there may be important gender differences in how quality of life is perceived. Yet, with some notable exceptions, quality of life research often lacks a gender perspective. One exception is Plagnol and Easterlin (2008) who show that aspirations and attainments play an important role in shaping well-being. Early in adult life, women are more likely than men to fulfil their aspirations concerning family life and material goods and express greater satisfaction in these domains than do men. In later life these gender differences are reversed and men come closer than women in satisfying their family and material aspirations and are the happier of the two genders. The question that Plagnol and Easterlin are unable to address, given the constraints of their data, is whether there are qualitative differences in what family life or material goods mean for men and women. This matters because if the goods aspired to are viewed differently, then how men and women best achieve quality of life may also be different.

It is important to take a life course perspective when examining people's perceptions of quality of life. It is not just the case that younger people's perceptions are likely to differ from older age groups, but also that people's perceptions of quality of life will change with important life course transitions, such as the move into a new job, becoming parents, retiring and so on. Another crucial insight of the life course perspective is that lives are interlinked. As psychologists have noted, people tend to live their lives in convoy (Antonucci and Akiyama 1987). What happens to one member of the household crucially affects the lives of other household members. This relational dimension is often ignored in quality of life research because most national surveys only interview one person from the household. Household panel surveys that interview all members of the household allow for the possibility of not only exploring how a person's own quality of life is dependent on what is happening in the lives of significant others, but also how quality of life is perceived differently by different household members.

Our aim in this chapter is to explore what people say matters for their own quality of life. This is a somewhat novel focus, because while there is much research exploring the influences on people's well-being or 
happiness, far less is known about how people perceive what is important for their own quality of life. Yet, as the Thomas theorem states, perceptions do matter: 'If men define situations as real they are real in their consequences' (Thomas and Thomas 1928: 572).

Our exploration of perceptions has four main analytical goals. The first is to explore both quantitatively and qualitatively how men and women differ in what they say is important. Second, we explore whether there are gender differences in the way men and women see their quality of life as bound up with others. There is a psychological literature suggesting that women are more relationally orientated than men. Recognition of the significance of intimacy and relationships with others, is something that Gilligan claims is gendered and 'is something women have known from the beginning' (Gilligan 1982: 17). Following Chodorow (1978), Gilligan sees the gender difference originating in early childhood with the different patterns of attachment and separation of girls and boys from mothers. For girls, identification with the mother leads to attachment being a more prevalent aspect of later relationships; whereas separation is the equivalent experience for males, who have to establish a distinct gender identity from the mother. Whatever the merits of such psychoanalytical theorising, the question of whether significant others play a more important role for women than for men in perceptions of quality of life is open to empirical investigation. Third, we investigate how perceptions of quality of life change with the transition to parenthood. Parenthood is perhaps the most important life course change in terms of its effect on the gender division of labour. Thus we expect gender differences in what matters before and after parenthood to be marked. Finally, we consider how the transition to retirement influences perceptions of quality of life. Retirement is likely to affect perceptions of quality of life differently for men and women, given the different gender balance in paid and unpaid work across the life course.

Before we present the results of our analysis we first describe the data used and explain the detailed coding exercise that was required to reach a descriptive understanding of quality of life. In an earlier study, we have used the example of perceptions of quality of life to argue that there is room for methodological advancement in panel surveys by including at least some qualitative elements in questionnaires through the use of openended questions (Scott et al. 2009) and have examined the comparability of individual subjective well-being measures (Plagnol and Scott 2008). Here we extend this work to show that perceptions of quality of life are not fixed but change over time. Moreover, we demonstrate that men and women have different perceptions of what matters, in ways that are bound up with their different gender roles across the life course. 


\section{PERCEPTIONS OF QUALITY OF LIFE: BRITISH HOUSEHOLD PANEL SUR VEY}

Our data are from the British Household Panel Survey which began in 1991 and is a multi-purpose study whose unique value resides in the fact that it: a) follows the same individuals over time, interviewing all household members on an annual basis; b) it is household-based, interviewing every adult member (16 and over) of the sample households; c) it contains sufficient cases for a meaningful analysis of sub-population groups such as different age groups, or different family types. The first wave of the panel consisted of some 5500 households and 10300 individuals, drawn from a proportionate representative sample of 250 postal areas in Great Britain (Taylor et al. 2007).

An open-ended question is routinely included at the end of the individual questionnaire. In Wave 7 (1997) and Wave 12 (2002), the question asked about people's quality of life was:

The final question asks you to think about things that are important to you. There is a lot of discussion these days about quality of life, yet that means different things to different people. Would you take a moment to think about what quality of life means to you, and tell me what things you consider are important for your own quality of life?

The interviewer was instructed to probe each mention in more detail with the prompt: 'In what ways is that important to you?'

Our development of a coding scheme for these verbatim responses proceeded as follows. As we were manipulating thousands of responses, some initial coding of themes was necessary in order to aid the development of our qualitative analysis. First, a detailed descriptive coding scheme was developed by the first author, which captured the full range of mentions across different domains such as health, family, finances, friends, home comforts, leisure, employment, freedom, time for self, environment and community. Each domain often had several sub-codes, for example, family is subdivided into four - partner/marriage, children and grandchildren, other family members and mentions of family in general. In all, the original BHPS coding frame lists 77 substantive codes (see Taylor et al. 2007: Appendix 3.18). Up to four mentions were coded in the verbatim responses. We then carried out extensive new qualitative analysis, using both the original verbatim responses and re-grouping the pre-coded material to better reflect the main themes that people mentioned (see the Appendix).

The next stage was to unpack precisely what things people considered to be important for their own quality of life. The descriptive results of our 
Table 9.1 Rank order of things which are important for your quality of life

\begin{tabular}{|c|c|c|c|c|c|c|}
\hline \multirow[t]{2}{*}{ Item } & \multicolumn{3}{|c|}{1997} & \multicolumn{3}{|c|}{2002} \\
\hline & $\begin{array}{l}\% \text { first } \\
\text { mention }\end{array}$ & $\begin{array}{c}\text { combine } \\
\%\end{array}$ & $\underset{\mathrm{n}}{\text { combined }}$ & $\begin{array}{c}\% \text { first } \\
\text { mention }\end{array}$ & $\begin{array}{c}\text { combine } \\
\%\end{array}$ & $\begin{array}{c}\text { ombined } \\
\mathrm{n}\end{array}$ \\
\hline Health & 36.6 & 53.1 & 4803 & 38.3 & 52.7 & 4361 \\
\hline Family & 11.0 & 40.3 & 3646 & 15.4 & 44.2 & 3660 \\
\hline Finance & 9.8 & 37.7 & 3414 & 8.2 & 33.9 & 2808 \\
\hline Happiness & 9.9 & 28.5 & 2580 & 9.2 & 25.6 & 2116 \\
\hline Friends & 3.6 & 20.5 & 1854 & 2.8 & 16.7 & 1379 \\
\hline Home comforts & 5.3 & 15.7 & 1417 & 4.0 & 12.0 & 989 \\
\hline Leisure & 3.1 & 15.4 & 1394 & 3.7 & 17.8 & 1474 \\
\hline Employment & 4.2 & 14.2 & 1287 & 2.7 & 9.6 & 795 \\
\hline Freedom & 2.8 & 7.3 & 659 & 3.0 & 8.8 & 730 \\
\hline Time for self & 3.1 & 7.2 & 651 & 3.6 & 9.9 & 818 \\
\hline $\begin{array}{l}\text { Miscellaneous } \\
\text { other }\end{array}$ & 1.9 & 7.2 & 648 & 2.1 & 8.4 & 693 \\
\hline $\begin{array}{l}\text { Other material } \\
\text { benefits }\end{array}$ & 1.2 & 6.6 & 595 & 1.1 & 5.8 & 478 \\
\hline $\begin{array}{l}\text { Environment, } \\
\text { community }\end{array}$ & 1.5 & 6.6 & 594 & 1.5 & 5.3 & 442 \\
\hline Other personal & 1.8 & 6.4 & 578 & 0.7 & 3.3 & 272 \\
\hline $\begin{array}{l}\text { Negative } \\
\text { mentions }\end{array}$ & 2.1 & 5.2 & 469 & 1.8 & 3.4 & 282 \\
\hline Spiritual, moral & 1.2 & 4.6 & 412 & 0.8 & 3.6 & 300 \\
\hline Don’t know & 1.0 & 1.0 & 93 & 1.0 & 1.0 & 82 \\
\hline $\mathrm{N}$ & 9047 & & & 8272 & & \\
\hline
\end{tabular}

Source: BHPS (with cross-sectional weights).

substantive re-grouping of the more detailed coding scheme are shown in Table 9.1. The first column and the fourth column show the responses people cited first in 1997 and 2002 respectively, with percentages adding to 100 per cent. Thus, in 1997, 37 per cent of people mention health as the first (or the only thing) they cite, and in 2002 the figure was 38 per cent. The second column (on which the rank order of the table is based) and the fifth column show the percentage of the samples who mention a particular response at all. Thus in 1997 53per cent of our sample mention health (the most frequently mentioned concern) whereas 47 per cent (not shown) do not. Similar figures are found for 2002, with 53 per cent again 
mentioning health. As up to four mentions were coded, these columns do not add to 100 per cent. We can see that three domains are mentioned by more than one third of participants: health ( 53 per cent both waves), family (40 per cent in 1997, 44 per cent in 2002) and finance ( 38 per cent in 1997 and 34 per cent in 2002). There are interesting things to be said about other domains mentioned, like, for example, the relatively low mentions of environment and community, which the literature suggests is a more prominent concern (Rapley 2003). However, this result may simply be due to the phrasing of the question, which may seem to give a steer towards more personal issues.

In our subsequent analysis we first consider the extent to which there are gender differences in what people perceive as important for quality of life. We then present further analysis of the three most mentioned categories in order to explore whether, regardless of whether or not there are quantitative differences in quality of life, men and women show qualitative differences in the way different domains matter. The graphs below are based on the combined data from 1997 and 2002 and we draw on both waves for illustrative quotes. We will return to examine the qualitative data longitudinally later in the chapter but, in the section that follows, our aim is to investigate gender similarities and differences in the range of meanings attached to each key domain.

\section{QUANTITATIVE AND QUALITATIVE ANALYSIS OF QUALITY OF LIFE}

Our analysis suggests that concepts of quality of life change at different stages of the life course. Both men and women mention health as being an important part of their own quality of life more often than any other item overall. However, at young ages both genders are more likely to mention family and finances than health (Table 9.2). Mentions of friends, home comforts and employment also are less pronounced among the older age groups, whereas the importance of leisure and freedom is more marked among older respondents. Here we focus on younger (15-25) and older (65 and over) age groups, in order to contrast the widest spread of generations. The full age-range responses are shown under 'all' (in columns 3 and 6). However, in the next section, we unpack how responses varied across the entire range of age groups. Almost all categories display significant gender differences, with women more likely than men to mention health, family, happiness and friends and less likely to mention finance, leisure and employment. The gender difference in mentions of home comforts is slight (although with these large numbers still statistically significant at $\mathrm{p}<.05$ ). 
Table 9.2 Quality of life mentions by gender and age, pooled data 1997 and 2002

\begin{tabular}{|c|c|c|c|c|c|c|}
\hline \multirow[t]{2}{*}{ Age } & \multicolumn{3}{|c|}{ Women } & \multicolumn{3}{|c|}{ Men } \\
\hline & $15-25$ & $\begin{array}{l}65 \text { and } \\
\text { over }\end{array}$ & all & $15-25$ & $\begin{array}{l}65 \text { and } \\
\text { over }\end{array}$ & all \\
\hline Health & 35.84 & 61.10 & 57.41 & 29.57 & 60.97 & 50.29 \\
\hline Family & 51.92 & 35.84 & 49.30 & 36.22 & 27.60 & 38.44 \\
\hline Finance & 39.72 & 20.86 & 33.30 & 43.72 & 27.60 & 38.83 \\
\hline Happiness & 32.23 & 17.68 & 29.71 & 26.28 & 17.38 & 24.96 \\
\hline Friends & 35.58 & 19.49 & 19.14 & 32.39 & 11.86 & 15.29 \\
\hline Home comforts & 18.10 & 13.64 & 14.39 & 16.82 & 11.43 & 13.45 \\
\hline Leisure & 11.36 & 22.45 & 15.15 & 19.21 & 23.78 & 19.66 \\
\hline Employment & 19.82 & 0.69 & 9.87 & 24.37 & 1.45 & 14.94 \\
\hline Freedom & 5.11 & 11.04 & 6.94 & 5.45 & 10.17 & 7.69 \\
\hline Time for self & 4.89 & 3.97 & 7.82 & 6.02 & 5.47 & 9.75 \\
\hline Miscellaneous other & 7.62 & 9.74 & 7.93 & 6.26 & 7.31 & 7.16 \\
\hline $\begin{array}{l}\text { Other material } \\
\text { benefits }\end{array}$ & 11.71 & 6.39 & 6.68 & 10.61 & 7.07 & 6.81 \\
\hline $\begin{array}{l}\text { Environment, } \\
\text { community }\end{array}$ & 2.47 & 3.72 & 3.86 & 4.83 & 7.02 & 6.86 \\
\hline Other personal & 6.47 & 4.58 & 4.90 & 6.98 & 4.31 & 4.91 \\
\hline Negative mentions & 1.98 & 5.20 & 3.83 & 3.01 & 5.13 & 4.57 \\
\hline Spiritual, moral & 2.11 & 8.19 & 4.28 & 2.68 & 6.44 & 3.90 \\
\hline Don’t know & 1.59 & 0.90 & 0.80 & 2.05 & 1.26 & 1.07 \\
\hline $\mathrm{N}$ & 2271 & 2771 & 14291 & 2093 & 2065 & 12037 \\
\hline
\end{tabular}

Source: BHPS (no weights).

Because our data are from two surveys of only five years apart, it is important to note that the percentages reported in Table 9.2 are based on individuals who belong to very different birth cohorts. Thus the observations for the lower age group (15-25 years) are from people who were born between 1972 and 1987, whereas members of the 65 and over age group were all born before 1937. It is possible that members of the younger cohort will place considerably less importance on health once they reach 65 than the older cohorts shown here, but the qualitative responses presented below make it apparent that there are pronounced life course differences. Similarly, it is possible that gender differences might diminish for future cohorts, but again, as our qualitative analysis shows, there are pronounced gender differences in what matters for quality of life across the life course. 


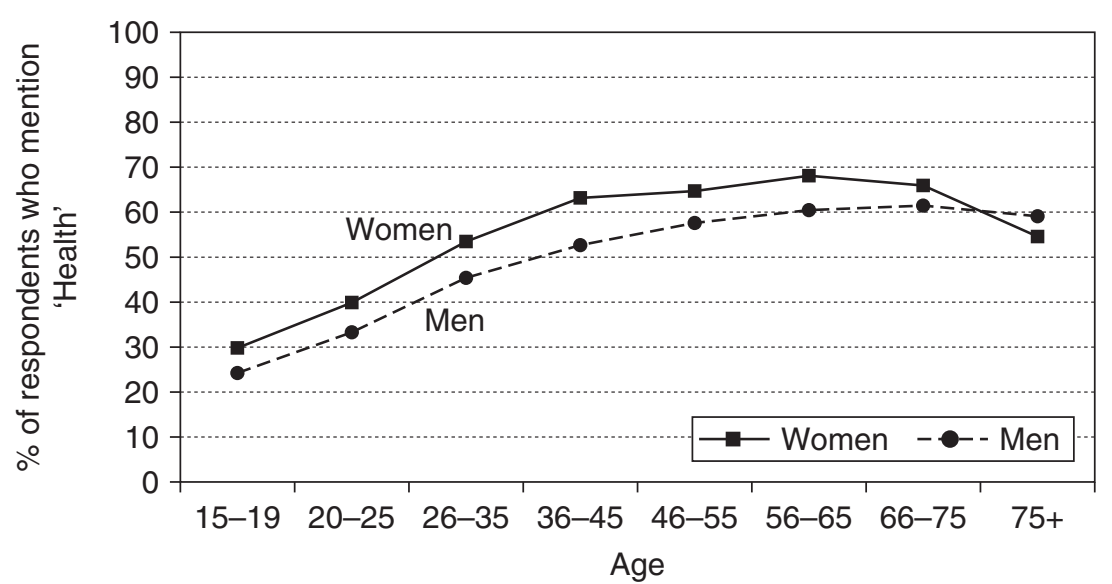

Figure 9.1 Percentage mentions of health by age and gender

\section{QUALITATIVE ANALYSIS OF KEY DOMAINS}

\section{Health}

There is a large body of literature on preference-based measures of quality of life that focuses on health (for example Lenert and Kaplan 2000). In our study, too, we found that the majority of statements in this domain showed a keen sense of the importance of good health as a foundation from which to build a reasonable quality of life, and examples of this awareness can be found across all groups: Josh, ${ }^{1} 17$, notes that 'without health you're nothing', likewise Lily, 67 notes 'If you've got your health that's all that's important'.

As Figure 9.1 makes clear, health is a more important factor for some age groups than others in assessing quality of life. It is a particular priority from the mid-30s onwards, which may reflect a growing awareness of decreasing energy levels as well as increasing functional difficulties. It may also, as we will discuss later, indicate that health becomes more salient for people when they have children themselves.

While younger participants tend to discuss health in the generic sense outlined above, older participants are more likely to mention specific ailments or declines in cognitive functioning. Older people focus on having their 'marbles' or keeping their 'mobility'. Thus our data confirm an emphasis that is already well documented in health-related quality of life literature (Bowling 1995). Joan, 61, said: 'I suffer from sciatica and high 
blood pressure so I know how much illness can affect my life and social activities'. Similarly, Will, 76, tells us: 'You need to have all your marbles; mobility is important and to have all your thinking facilities.'

However, while deterioration in the participant's own health becomes more pronounced in older age groups, another interesting finding was the way in which the role of the older person as the carer of a partner in illhealth also has a bearing on their assessment of their own quality of life. June, 75 , reflects on the impact of her husband's illness on her own quality of life: 'I haven't got any quality [of life] at the moment as my husband has Alzheimer's.' Similarly, men in the caring role also note the importance of the health and well-being of significant others: Phillip, 63, tells us: 'If Ann [participant's wife] was better it would help. Ann is still waiting for her operation.'

While the strains of being an older carer are well known, we find some examples of this relational aspect of health echoed by both women and men in all age groups. Jack, 20, notes the importance of 'My family's health and well-being, including my own' to his quality of life. Sarah, 38, answers, 'Children's health: because life is tough when they're not well - everything goes much smoother when they're well.' This 'other orientation' in the importance of health for well-being is something that is easily overlooked in the quality of life literature, which tends to focus solely on the individual.

\section{Family}

Our next domain, family, continues the theme of the relationship between self and other in understanding lay evaluations of quality of life. Some argue that demographic changes, coupled with social and economic changes, such as geographical mobility, increased divorce rates, singleparenthood, women's increased involvement in paid work, and supposed increases in individualism make 'family' less important to people, both emotionally and materially, than in previous eras (Beck 1992; Giddens 1992). However, there is a significant amount of literature which critiques and problematises these claims (Crompton 2006; Duncan and Smith 2006; Nolan and Scott 2006; Williams 2004). In our study, too, we find further empirical evidence of the continuing importance of family, particularly for women. As Figure 9.2 shows, in all age groups women are more likely than men to mention family as important for their quality of life (though we would not wish to over-emphasise the difference, as family is clearly important to men too). Interestingly, however, for women in particular, it is the under-46s, those who are most likely to live in households with two generations, who are most likely to mention family. 


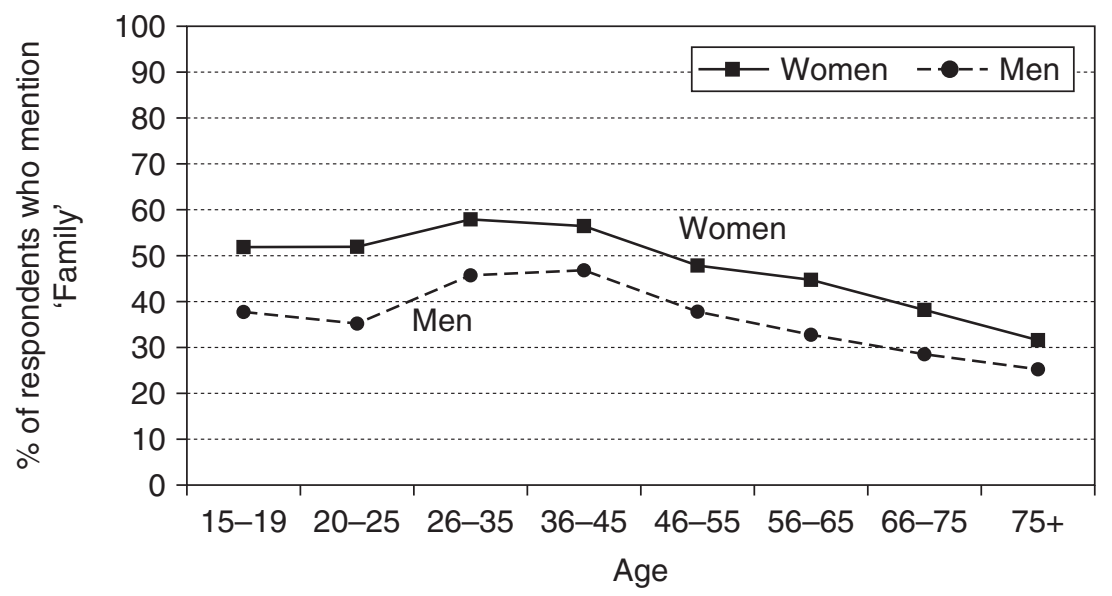

Figure 9.2 Percentage mentions of family by age and gender

But what precisely do people talk about in relation to family and quality of life, and what differences do we find between women and men in different age groups? First, we find a common generic appreciation of family that echoes across gender and age groups: Paul, 27, notes: 'The family's the most important part of my life' and June, 61, describes the importance of 'Having family around you'. That said, however, there are, of course, differences in the kinds of support given and received by different family members across the life course and, not surprisingly, in the under-25s we find reference to families as the providers of moral and material support: Edward, 19, notes that family is important to his quality of life because: 'My family looked after me for a lot of my life'. Similarly Cindy, 21, values family because 'They give me moral support'.

There were also some fairly gender-stereotypical responses in relation to family and quality of life. In the 26-45 age group, we find more women than men mentioning the importance of children's well-being, and men more likely than women to link the importance of family to their role as breadwinners. There were, of course, occasions when women discussed the importance of their breadwinning role for their family (see the following section on finance) and when men mentioned their concern with their children's well-being, but the following are typical statements illustrating gender differences: Amber, 28, for example, tells us that what is important for her quality of life is: 'My children. How they are, how they eat and dress. Their education.' And Luke, 41, notes that for him, quality of life means: 'A secure job [which] enables me to buy things for my family'. We see further examples of this breadwinning theme as we turn to mentions of finance. 


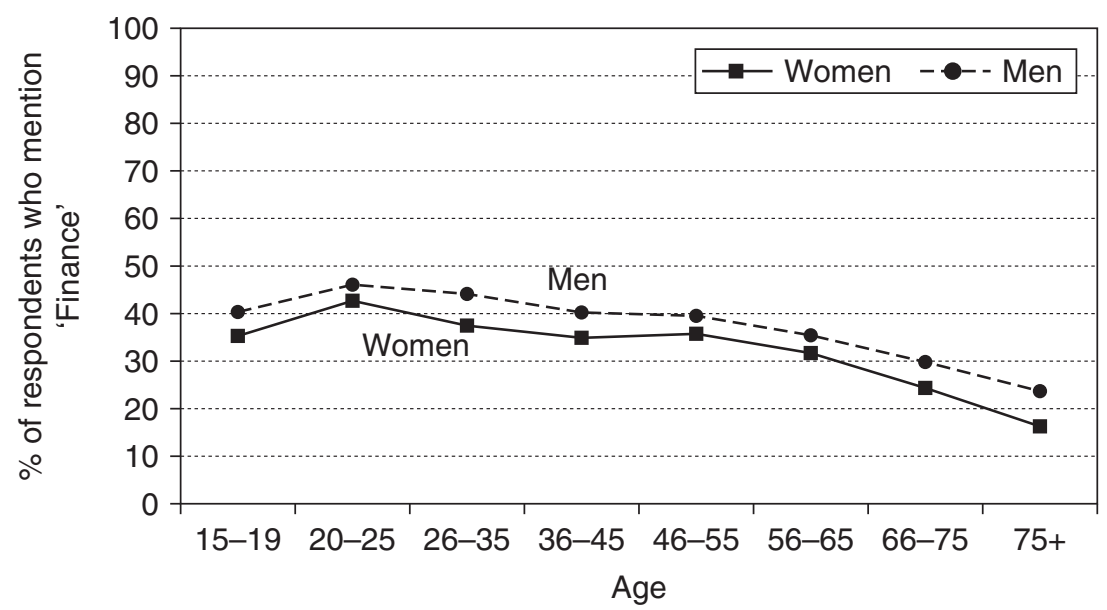

Figure 9.3 Percentage mentions of finance by age and gender

\section{Finance}

It is sometimes claimed that consumerism and lifestyle aspirations increasingly govern values and quality of life (Rapley 2003). However, while over a third of our sample mentioned finance-related matters as important for their quality of life, the key theme to emerge from our qualitative analysis highlighted the importance of 'not worrying about money' or 'not struggling'. We don't find people dreaming of winning the lottery, nor do we find responses that emphasise the importance of buying luxury cars, designer clothes or other consumer goods to ensure a good quality of life. Rather, typical quotes include: 'Not having to struggle financially' (Duncan, 33); 'To not worry about paying bills and have money for extra meals and holidays' (Mandy, 38); 'Having enough money not to have to struggle' (Ralph, 51).

Examining group differences in this category, Figure 9.3 illustrates that, in all age groups, men are more likely than women to mention finance, although frequency of mentions across the life course is very similar for men and women. Interestingly, however, qualitative analysis shows that men in the 20-35 age range discuss finance in relation to quality of life in the sense of being free from debt. From 36 to 54, however, an additional theme emerges which illustrates, once again, the importance of the relationship between finance and breadwinning identity. Rhys, 43, discusses finances in terms of 'Earning a decent wage; to support my family financially'. Likewise Roy, 38, notes, 'I would say not having to struggle. Being able to provide for the children and ourselves.' 
It is important to highlight the ways in which each of our core themes are interlinked. While counting the number of mentions of each theme provides us with a stronger base from which to make generalisations, this form of 'chunking' qualitative data can gloss over important information about processes. For example, our qualitative analysis shows that health is often important because individuals need good health to care for others, both financially and emotionally. To illustrate the point further, men in mid-life mentioned health as important for work, which, in turn, was central to their breadwinning role. As Sebastian notes, quality of life consists of 'My health, so I can run my business and provide for my family'. Likewise Phillipa, when asked why her health was important to quality of life, noted the importance of good health for fulfilling her caring roles, 'I need to keep my health to look after my mam and my husband'. Aged 26, and following a divorce, Lily notes the importance of being healthy because she needed to be 'able to look after the children by myself'. Similarly, Charlie, 39 and divorced, says, 'I need my health as I have 4 children to look after'. In the following section we examine the influence of a key life transition: family formation on perceptions of quality of life.

\section{LIFE COURSE TRANSITIONS AND CHANGING EVALUATIONS OF QUALITY OF LIFE}

\section{Family Formation and Changing Evaluations of Quality of Life}

As indicated in the quotations above, the way people evaluate the wellbeing of others is, in fact, central to their assessment of their own quality of life. In this section, we will focus specifically on how the transition to partnership and parenthood influences an individual's perception of what matters for quality of life. This is mainly because it seems likely that 'other orientation' becomes more significant at this point in the life course. Not surprisingly, however, we find that this transition is somewhat different for women and men.

There were 51 women who were single and under 40 in 1997 and who were living with both a partner and a child five years later in 2002. There are clear indicators in the qualitative data of the way in which family formation brings changes to evaluations of what is important for quality of life. For example, in 1997, Olive emphasises 'financial security, health and peace of mind'. In 2002, however, while she still emphasises financial security, she also notes the importance to her quality of life that 'my son and immediate family are happy'. Likewise, Sally mentioned financial and 
emotional security in 1997 , but, in 2002, the first thing she discusses is 'spending time with family at home'.

The change in definitions of quality of life brought on by motherhood can be illustrated by the following examples. Eleanor's priorities in 1997 were 'health and work': 'giving up smoking, health generally, expanding my career, making myself money, my future generally'. In 2002, however, her concerns are: 'my son and a good family life - that's all that's important to me'. For Mary her priorities in 1997 were 'happiness and standard of living'. In 2002, she emphasises the importance of 'the health of my child and family - they're my whole life, what would I do without them.' Similarly, Carol undergoes a shift from placing importance on 'good friends and a steady income' in her first interview, to 'being with family, see baby grow up and being with partner'.

Forming a family also changes the way in which men evaluate their quality of life. There were 79 men who were single and aged under 40 in 1997 and in a couple with at least one child in 2002. Predictably, the way priorities change for men is often linked to becoming the 'breadwinner'. For example when Andrew was aged 26, what was important to his quality of life was that he could 'go out and enjoy myself'. Aged 31 , as a father, he now wants to be 'comfortable, not struggling as we do at the moment. If I could get a better job, everything will be fine'. Billy, 23, was interested in a 'comfortable income, nice food, nice place to live, nice clothes, spending time with my girlfriend'. But aged 28 he was focused on 'making a living to keep us all happy'. Likewise, aged 22, Martin noted the importance of 'going to work, money is important, a stable family'; five years later he defines quality of life as 'providing for my family, make sure they are happy. If the family is happy, that's all we need.'

But the transition to family did not just influence quality of life in relation to the importance of 'providing'. The intimacy and companionship of family life were also now more salient to definitions of quality of life. Aged 29, Ian first described quality of life as 'being able to go out and enjoy yourself'; later he focuses on 'being with my family; they keep me happy; make me laugh'. Similarly, Darren, 24, wants 'money, friends, [good] neighbourhood, health, socializing and confidence'. Aged 29, he lists 'my daughter, my wife, money, health: now Hannah and Vanda are in my life I couldn't be without them'.

Of course, there were both men and women who remained consistent in their views across the waves, or whose perceptions changed in ways which are not linked with their change in family status. Nevertheless, for most people the transition to partnership and parenthood brings different priorities, and quality of life had become more 'other orientated'. 


\section{Quality of Life before and after Retirement}

Our final analysis examines whether people's perceptions of quality of life shift before and after retirement, which is, like entering parenthood, an important life stage transition. We also explore qualitatively how men and women differ in their perceptions of quality of life, before and after retirement, and how this might relate to the different gender roles concerning priorities given to the breadwinner role and to family care. In addition, we examine the claim of Laslett (1989) that the map of life has to be redrawn, and that the 'third age' - the period when employment has ended and children have grown - should be 'the crown of life', when people have greater freedom to realise their own personal objectives. The theory has been criticised, not least because Laslett is seen as giving undue focus to the elite group who benefit from lifelong learning and self-improvement. Our findings on the Laslett hypothesis can be summarised very briefly. Not surprisingly, in our representative sample, there are a handful of mentions from both women and men of the benefits they accrue from time for reading and travel and education - but these are the exception, not the rule.

As can be seen in Table 9.3, there are systematic differences between men and women in how perceptions of what matters for quality of life changes in the years before and after retirement. Among the 279 women who retired between 1997 and 2002, the dominant quality of life mentions in both years are health and family. However, health mentions decline, whereas family mentions slightly increase. For the 196 men who retired in the same period, health mentions increase, but family mentions slightly decrease. Health and finance are the two main mentions for men following retirement. When asked to elaborate on why these are important, a common response is that the reasons are so obvious that they hardly need elaboration - after all 'it's no good being ill or poor'. As we saw in Figure 9.3, more men mention finance than women throughout the life course, and this gender difference continues post-retirement.

However, men's mentions of finance often display a continuity with their former breadwinner role, and the focus of their response is about maintaining a reasonable standard of living or about sufficient financial support for other family members. Previously published analysis using BHPS data show that men are more likely than women to provide financial help to adult children, while women are more likely than men to provide regular care for grandchildren (Nolan and Scott 2006). In the current analysis it is quite clear that for many men and women, taking care of others is perceived as being important. In other words, people perceive relationships as mattering hugely for one's own quality of life.

Both women and men talk of the importance of grandchildren for quality 
Table 9.3 Quality of life mentions by men and women who were selfemployed or in paid employment in 1997 and retired in 2002

\begin{tabular}{lrrrrr}
\hline \multirow{2}{*}{ Mention } & \multicolumn{2}{c}{ Women } & & \multicolumn{2}{c}{ Men } \\
\cline { 2 - 3 } \cline { 5 - 6 } & 1997 & 2002 & & 1997 & 2002 \\
\hline Health & 71.34 & 63.06 & & 52.35 & 69.80 \\
Family & 38.22 & 45.22 & & 37.58 & 30.87 \\
Finance & 38.85 & 26.11 & & 35.57 & 44.30 \\
Happiness & 36.31 & 21.66 & & 25.50 & 18.12 \\
Friends & 22.93 & 17.20 & & 14.77 & 13.42 \\
Leisure & 14.01 & 19.11 & & 24.16 & 18.79 \\
Home comforts & 12.10 & 10.83 & & 16.78 & 11.41 \\
Freedom & 7.64 & 12.10 & & 10.74 & 9.40 \\
Employment & 10.19 & 1.27 & & 18.12 & 1.34 \\
Misc other & 5.10 & 12.10 & & 7.38 & 9.40 \\
Spiritual & 5.10 & 5.10 & & 3.36 & 4.03 \\
Negatives & 3.18 & 1.27 & & 7.38 & 3.36 \\
Environment & 5.73 & 7.01 & & 12.75 & 12.75 \\
Time self & 6.37 & 6.37 & & 8.05 & 9.40 \\
Other personal & 3.18 & 1.91 & & 6.04 & 2.68 \\
Other material & 1.27 & 8.28 & & 5.37 & 4.03 \\
& & & & & \\
N & 157 & 157 & & 149 & 149 \\
\hline
\end{tabular}

Source: BHPS (no weights).

of life, albeit with some important gender differences. A typical male response is from Mike, aged 62, who spoke of his grandchildren as 'taking years off me', and goes on to say, 'I have time for them that I didn't have for my own children'. This response captures succinctly the changing image of what a 'good father' involves. For men of Mike's generation a good provider was a good father. Today, good fathers are expected to spend time with children. Needless to say, there are no equivalent responses given by women; whatever their paid work hours, mothers are expected to provide care for children. Perhaps this helps explain an intriguing quantitative gender difference - for women, post-retirement mentions of the importance of leisure increase, whereas after retirement men's mentions of leisure decrease.

\section{CONCLUSIONS}

In this chapter we explore people's perceptions of what matters for their quality of life. The three most common themes mentioned are health, 
family and finance. One common aspect of health mentions was the very high degree of emphasis on the health of others. The importance of relationships, not surprisingly, comes through very clearly in mentions of family. Here there is strong evidence of gender-stereotypical responses. Men are more likely than women to link the importance of family to their role of breadwinner. Moreover, men's mentions of finance are often bound up with their breadwinner role. Thus one of our most important findings is that people see their own quality of life as strongly bound up with the quality of life of significant others. The existing literature often is overly individualistic and fails to give sufficient attention to the 'other orientation' that is frequently emphasised by both men and women.

A second finding of this study is that quality of life is a process that changes as people age and move across different life course stages. For example, as people move into partnership and parenthood their perceptions of the importance of others becomes even more marked. Similarly, when people move from employment into retirement, quality of life perceptions shift once again. Moreover, they shift in ways that are crucially related to the distinctive gender roles of men and women.

Throughout our analysis we found strong gender differences in the way men and women talked about their family and work responsibilities and how these connect to quality of life. This has important ramifications for policy makers who are concerned to address the work-life balance issue, which has come to the fore both in the UK and in Europe. Often discourse on work-life balance and quality of life is framed in gender-neutral terms. However, any policy concerned with the allocation of paid and unpaid work must take into account the pronounced gender differences. Men and women's different caring and breadwinning roles lead to important differences in the way they perceive quality of life.

Yet both men and women perceive their own quality of life as being bound up with the well-being of others. Thus our data would support the view that one policy priority should be to tackle the so-called "care deficit' which in part results from the long work-hour culture of men and the increased labour force participation of women. We argued at the outset that the Thomas theorem applies and that studying perceptions is important, because if people perceive something to be real, then it is real in its consequences. If this is the case, then steps taken to support both men and women's actions in caring for others will benefit the quality of life for all. 


\section{NOTE}

1. For stylistic reasons we use pseudonyms when discussing quotations. To protect anonymity, participants can only be identified by a unique number in the data set.

\section{REFERENCES}

Antonucci, T. and H. Akiyama (1987), 'Social networks in adult life and a preliminary examination of the convoy model', Journal of Gerontology, 42(5), 519-27.

Beck, U. (1992), Risk Society: Towards a New Modernity, London: Sage.

Bliss, C. (1996), 'Economics of the environment', in A. Offer (ed.), In Pursuit of the Quality of Life, Oxford: Clarendon Press, pp. 66-87.

Bowling, A. (1995), 'What things are important in people's lives: a survey of the public's judgement to inform scales of health related quality of life', Social Science and Medicine, 41(1), 1447-62.

Chodorow, N. (1978), The Reproduction of Mothering, Berkeley: University of California.

Crompton, R. (2006), Employment and the Family: the Reconfiguration of Work and Family Life in Contemporary Societies. Cambridge: Cambridge University Press.

Duncan, S. and D. Smith (2006), 'Individualisation versus the geography of "new" families', 21 st Century Society, 1(2), 167-89.

Easterlin, R.A. (2001) 'Income and happiness: towards a unified theory', Economic Journal, 111, 465-84.

Elliott, S and D. Umberson (2004), 'Recent demographic trends in the US and implications for well-being', in J. Scott, J. Treas and M. Richards (eds), Blackwell Companion to Sociology of Families, Oxford: Blackwell.

Gallie, D. (1996), 'The quality of employment: perspectives and problems', in A. Offer (ed.), In Pursuit of Quality of Life, Oxford: Clarendon Press, pp. 163-87.

Gershuny, J. and B. Halpin (1996), 'Time use: quality of life and process benefits', in A. Offer (ed.), In Pursuit of Quality the of Life, Oxford: Clarendon Press, pp. $188-210$.

Giddens, A. (1992), The Transformation of Intimacy: Sexuality, Love and Eroticism in Modern Societies, Cambridge: Polity Press.

Gilligan, C. (1982), In a Different Voice: Psychological Theory and Women's Development, Cambridge: Harvard University Press.

Laslett, P. (1989), A Fresh Map of Life, London: George Weidenfeld and Nicolson Ltd.

Lenert, L. and R. Kaplan (2000), 'Validity and interpretation of preference-based measures of health related quality of life', Medical Care, Supplement II, 38(9), $138-50$.

Marmot, M. (2004), Status Syndrome: How your Social Standing Directly Affects your Health and Life Expectancy, London: Bloomsbury.

Nolan, J. and J. Scott (2006), 'Gender and kinship in contemporary Britain', in M. Richards (ed.), Kinship: Relationships and Law in a Changing Society, London: Hart.

Plagnol, A.C. and R.A. Easterlin(2008), 'Aspirations, attainments, and satisfaction: 
life cycle differences between American women and men', Journal of Happiness Studies 9(4), 601-19.

Plagnol, A.C. and J. Scott (2008), 'Individual perceptions of quality of life over the life course: implications for the comparability of subjective well-being measures', GeNet working Papers No. 33.

Rapley, M. (2003), Quality of Life Research: A Critical Introduction, London: Sage.

Scott, J., J. Nolan and A.C. Plagnol (2009), 'Panel data and open-ended questions: understanding perceptions of quality of life', special issue (edited by R. Wiles, N. Bardsley, and G. Crow), $21^{\text {st }}$ Century Sociology, forthcoming.

Sirgy, M.J., A.C. Michalos, A.L. Ferriss, R.A. Easterlin, D. Patrick and W. Pavot (2006), 'The quality-of-life (QOL) research movement: past, present, and future', Social Indicators Research, 76(3), 343-466.

Taylor, M.F., J. Brice, N. Buck and E. Prentice-Lane (eds) (2007), British Household Panel Survey User Manual Volume A: Introduction, Technical Report and Appendices, Colchester: University of Essex.

Thomas, W.I. and D.S. Thomas (1928), The Child in America: Behavior Problems and Programs, New York: Knopf.

Wilkinson, R.G. (1996), Unhealthy Societies: the Afflictions of Inequality, London: Routledge.

Williams, F. (2004), Rethinking Families, London: Calouste Gulbenkian Foundation. 


\section{APPENDIX: QUALITY OF LIFE PERCEPTION OF WHAT MATTERS*}

Question:

'Would you take a moment to think about what "quality of life" means to you, and tell me what things you consider are important for your own quality of life?'

Coding of mentions: based on BHPS manual, Appendix 3.18

1. Health: good health, mobility, living and breathing, personal welfare.

2. Family: children and grandchildren, partner, marriage, other family members, family in general.

3. Finance: finances, money, standard of living.

4. Happiness: happiness, peace of mind, security.

5. Friends: friends, friendship.

6. Leisure: food, cooking, having a drink, music, radio, theatre, sports, walking, exercise, TV, gardening, nature in general, reading, writing, painting, travel, incl. holidays abroad, getting out and about (going places generally), other leisure/pleasure activities (not elsewhere codable), exercising.

7. Home comforts: home comforts, roof over head, regular meals, domestic hygiene.

8. Employment: employment, job satisfaction.

9. Misc other: Safety, lack of fear, neighbours, pets, other relationships, other positive mentions, other.

10. Freedom: freedom, independence.

11. Time self: time for self, not too overworked, life in balance, sleep, no stress.

12. Other material: consumption, shopping, getting new things, car, transport, education (own, children's, standard of system in general), other material benefits.

13. Other personal: Other personal characteristics (not elsewhere specified), love, sense of humour, personal cleanliness.

14. Spiritual: religion, treating others well, equality, tolerance, helping others, voluntary work, community participation, political activities, other spiritual, moral, community aspects, law and order.

15. Environment: good recreational facilities, neighbourhood-specific rural/urban benefits, neighbourhood - general mention, likes area or neighbourhood, environment, lack of pollution, general mention of 
environment, lack of crime, safe area, climate, weather, other local/ environment mentions (not elsewhere codable), news and current affairs.

16. Negatives: (this could be by implication, i.e. need more/better) need better personal characteristics - less worry, better health, more happiness; need better material characteristics - more money, better job; more leisure, recreation; more morality, spiritual, community spirit; better relationships; improvements in locality, environment, e.g. less crime, less crowds; other negative mentions (not elsewhere codable), need more time.

\section{NOTE}

* See Taylor et al. (2007), Appendix 3.18 for the full list of possible mentions. 